\title{
DUKUNGAN KELUARGA DALAM PEMBERIAN ASI EKSKLUSIF
}

Indah Sulistyowati, Oktaviani Cahyaningsih, Novita Alfiani

Prodi D-III Kebidanan STIKES Widya Husada Semarang, Jl. Subali Raya No. 12 Krapyak Semarang, (024) 7612988

indahs_17610@yahoo.com, oqt4_viani@yahoo.co.id, novitaalfians29@yahoo.co.id

\begin{abstract}
ABSTRAK
Pemberian ASI Eksklusif pada bayi 0-6 bulan di Kota Semarang telah mencapai target Renstra Kota Semarang $(65,20 \%)$. Namun demikian pencapaian dalam program ASI Eksklusif ini harus mendapatkan perhatian khusus agar mencapai $100 \%$. Dukungan keluarga merupakan faktor eksternal yang besar pengaruhnya terhadap keberhasilan ASI Eksklusif. Adanya dukungan keluarga terutama suami akan memberikan dampak peningkatan rasa percaya diri atau motivasi ibu dalam menyusui. Tujuan penelitian untuk mengetahui hubungan pengetahuan dan dukungan keluarga terhadap pemberian ASI Eksklusif di RW I Tambakharjo Kota Semarang. Jenis penelitian observasional dengan metode penelitian survei analitik. Populasi adalah semua keluarga yang memiliki bayi usia 5-24 bulan di RW I Kelurahan Tambakharjo Kota Semarang dengan sampel sejumlah 35 orang. Pengumpulan data menggunakan kuesioner. Analisis bivariate menggunakan uji ChiSquare. Hasil penelitian sebagian besar responden memiliki pengetahuan tentang ASI Eksklusif yang kurang (94.3\%), sebagian besar responden tidak mendukung pemberian ASI Eksklusif (56.6\%) dan sebagian besar responden tidak memberikan ASI Eksklusif (62.9\%) dan hasil uji Chi Square nilai $\rho$ value $=0,031$ dan $\rho$ value $=0,007<0,05$. Ada Hubungan pengetahuan dan dukungna keluarga terhadap pemberian ASI Eksklusif.
\end{abstract}

Kata kunci : ASI Eksklusif ; dukungan; pengetahuan

\section{FAMILY SUPPORT IN EXCLUSIVE BREASTFEEDING}

\begin{abstract}
Exclusive breastfeeding for infants 0-6 months in the city of Semarang has reached the target of the Renstra of the City of Semarang (65.20\%). However, the achievements in this Exclusive Breastfeeding program must receive special attention in order to reach 100\%. Family support is an external factor that has a big influence on the success of exclusive breastfeeding. The existence of family support, especially the husband will have an impact on increasing the confidence or motivation of mothers in breastfeeding. The purpose of this study was to determine the relationship of knowledge and family support for exclusive breastfeeding in Semarang City. This type of observational research was analytic survey research method. The population were all families who have babies aged 5-24 months in citizen Associations I Tambakharjo, Semarang City with a sample of 35 people. Data collection used a questionnaire. Bivariate analysis used Chi-Square test. The results of the study most of the respondents have less knowledge about exclusive breastfeeding (94.3\%), most respondents do not support exclusive breastfeeding (56.6\%) and most respondents do not provide exclusive breastfeeding (62.9\%) and Chi Square test results $\rho$ value $=0.031$ and $\rho$ value $=0.007<0.05$. There is a relationship of knowledge and family support for exclusive breastfeeding.
\end{abstract}

Keywords: exclusive breastfeeding; support; knowledge 


\section{LATAR BELAKANG}

Air Susu Ibu (ASI) merupakan makanan yang terbaik untuk bayi. ASI tidak dapat digantikan oleh makanan ataupun minuman manapun, karena ASI mengandung zat gizi yang paling tepat, lengkap dan selalu menyesuaikan dengan kebutuhan bayi setiap saat. Sayangnya, walaupun pemerintah telah menghimbau pemberian ASI Eksklusif, angka pemberian ASI Eksklusif di Indonesia masih rendah. Berdasarkan Survei Demografi Kesehatan Indonesia (SDKI) 2002, hanya $3,7 \%$ bayi yang memperoleh ASI pada hari pertama. Sedangkan pemberian ASI pada bayi umur kurang 2 bulan sebesar $64 \%$, antara 2-3 bulan $45,5 \%$, antara 4-5 bulan 13,9 dan antara 6-7 bulan 7,8\%. Sementara itu cakupan pemberian susu formula meningkat 3 kali lipat dalam kurun waktu antara 1997 sebesar $10,8 \%$ menjadi $32,4 \%$ pada tahun 2002. Sementara ini dari Survei Demografi dan Kesehatan Indonesia (SDKI) tahun 2012 mengumpulkan data tentang pemberian makanan pada bayi untuk semua anak terakhir yang dilahirkan ibu dalam kurun waktu dua tahun sebelum survey, menunjukkan bahwa hanya $27 \%$ bayi umur 4-5 bulan mendapat ASI Eksklusif (tanpa tambahan makanan atau minuman lain).

Dukungan keluarga merupakan faktor eksternal yang paling besar pengaruhnya terhadap keberhasilan ASI Eksklusif. Adanya dukungan keluarga terutama suami maka akan berdampak pada peningkatan rasa percaya diri atau motivasi dari ibu dalam menyusui. Suririnah (2009) mengatakan bahwa motivasi seorang ibu sangat menentukan dalam pemberian ASI Eksklusif selama 6 bulan. Disebutkan bahwa dorongan dan dukungan dari pemerintah, petugas kesehatan dan dukungan keluarga menjadi penentu timbulnya motivasi ibu dalam menyusui.

Berdasarkan hasil laporan Puskesmas di Kota Semarang tahun 2018, pemberian ASI Eksklusif pada bayi umur 0-6 bulan sejumlah 10.733 bayi atau $68,22 \%$. Pemberian ASI Eksklusif pada bayi $0-6$ bulan di Kota Semarang telah mencapai target Renstra Kota Semarang $(65,20 \%)$. Hal ini disebabkan karena adanya komitmen petugas kesehatan untuk membantu ibu yang mengalami kesulitan dalam menyusui, ada peningkatan pengetahuan ibu tentang manfaat menyusui dan cara menyusui yang tepat dan dukungan dari keluarga, serta dengan adanya sosialisasi terkait Peraturan Walikota Semarang (Perwal) No. 7 Tanggal 16 Januari 2013 tentang Program Peningkatan Pemberian ASI Eksklusif di Kota Semarang. Namun demikian pencapaian dalam program ASI Eksklusif ini harus mendapatkan perhatian khusus dan memerlukan pemikiran dalam mencari upayaupaya terobosan serta tindakan nyata yang harus dilakukan oleh provider di bidang kesehatan dan semua komponen masyarakat dalam rangka penyampaian informasi maupun sosialisasi guna meningkatkan pengetahuan dan kesadaran masyarakat.

Berdasarkan paparan diatas, maka penulis tertarik melakukan penelitian dengan tujuan mengetahui hubungan pengetahuan tentang ASI Eksklusif dan dukungan keluarga terhadap pemberian ASI Eksklusif di RW I Kelurahan Tambakharjo Kecamatan Semarang Barat Kota Semarang.

\section{METODE}

Jenis penelitian yang digunakan adalah observasional dengan metode penelitian survei analitik yaitu survey atau penelitian yang mencoba menggali bagaimana dan mengapa fenomena kesehatan itu terjadi. Kemudian melakukan analisis dinamika korelasi antara fenomena, baik antara faktor risiko dengan faktor efek, antar faktor risiko, maupun antar faktor efek, dimana peneliti hanya melakukan observasi tanpa memberikan intervensi pada variabel yang diteliti. Sedangkan pendekatan yang digunakan adalah pendekatan cross sectional dimana cara pengambilan data variabel bebas dan variabel terikat dilakukan sekali waktu pada saat yang bersamaan.

Populasi dalam penelitian ini adalah semua keluarga yang memiliki bayi usia 5-24 bulan di RW I Kelurahan Tambakharjo Kecamatan Semarang Barat Kota Semarang. Sampel dalam penelitian ini adalah semua keluarga yang memiliki bayi usia 5-24 bulan di RW I 
Kelurahan Tambakharjo Kecamatan Semarang Barat Kota Semarang sejumlah 35 orang dengan teknik sampling jenuh. Variabel dalam penelitian ini terdiri dari variabel bebas yaitu pengetahuan tentang ASI Eksklusif dan dukungan keluarga dalam pemberian ASI Eksklusif, serta variabel terikat yaitu pemberian ASI Eksklusif. Instrument penelitian yang digunakan adalah kuesioner. Analisis data terdiri dari analisis univariat yang menghasilkan distribusi dan persentase serta analisis bivariat yang menggunakan uji chi square.

HASIL

\section{Tabel 1 Distribusi Frekuensi Responden Berdasarkan Pemberian ASI Eksklusif $(n=35)$}

\begin{tabular}{lcc}
\hline \multicolumn{1}{c}{ Perilaku } & Frekuensi & Persentase (\%) \\
\hline Tidak & 22 & 62.9 \\
Ya & 13 & 37.1 \\
\hline \multicolumn{1}{c}{ Jumlah } & 35 & 100 \\
\hline
\end{tabular}

Tabel 1 menunjukkan bahwa sebagian besar responden tidak memberikan ASI eksklusif sebanyak 22 orang (62.9\%) dan yang memberikan ASI eksklusif sebanyak 13 orang $(37.1 \%)$.

Hasil penelitian analisis univariat dan bivariat hubungan Pengetahuan Terhadap Pemberian ASI Eksklusif di Kelurahan Tambakharjo Kota Semarang diuraikan secara ringkas pada tabel 2.

\section{Tabel 2 Hubungan Pengetahuan Tentang ASI Eksklusif Terhadap Pemberian ASI Eksklusif ( $n=35)$}

\begin{tabular}{ccccccc}
\hline \multirow{2}{*}{$\begin{array}{c}\text { Penge- } \\
\text { tahuan }\end{array}$} & \multicolumn{4}{c}{$\begin{array}{c}\text { Pemberian ASI } \\
\text { Eksklusif }\end{array}$} & \multirow{2}{*}{$\begin{array}{c}\text { Juml } \\
\text { ah }\end{array}$} & $\begin{array}{c}\boldsymbol{P} \\
\text { value }\end{array}$ \\
\cline { 2 - 5 } & \multicolumn{2}{c}{ Tidak } & \multicolumn{2}{c}{ Ya } & & \\
\cline { 2 - 5 } & $\mathbf{f}$ & $\%$ & $\mathbf{f}$ & $\%$ & & \\
\hline Kurang & 22 & 66.7 & 11 & 33.3 & 33 & 0.031 \\
Baik & 0 & 0 & 2 & 100 & 2 & \\
\hline Jumlah & 22 & 62.9 & 13 & 37.1 & 35 & \\
\hline
\end{tabular}

Tabel 1 menunjukkan bahwa sebagian besar responden mempunyai pengetahuan yang kurang sebanyak 33 orang (94.3\%). Responden dengan pengetahuan kurang sebagian besar tidak memberikan ASI eksklusif sebanyak 22 (66.7\%). Sedangkan responden dengan pengetahuan baik semuanya memberikan ASI eksklusif. Hasil penelitian meunjukkan nilai $\rho$ value $=0.031<$ 0,05 , artinya $\mathrm{Ha}$ diterima sehingga ada hubungan pengetahuan tentang ASI eksklusif terhadap pemberian ASI Eksklusif di RW I Kelurahan Tambakharjo Kecamatan Semarang Barat Kota Semarang.

\section{Tabel 3 Hubungan Dukungan Keluarga dalam Pemberian ASI Eksklusif Terhadap Pemberian ASI Eksklusif $(n=35)$}

\begin{tabular}{|c|c|c|c|c|c|c|}
\hline \multirow[t]{3}{*}{$\begin{array}{c}\text { Dukungan } \\
\text { Keluarga }\end{array}$} & \multicolumn{4}{|c|}{$\begin{array}{c}\text { Pemberian ASI } \\
\text { Eksklusif }\end{array}$} & \multirow[t]{2}{*}{$\begin{array}{c}\text { Juml } \\
\text { ah }\end{array}$} & \multirow{3}{*}{$\begin{array}{c}P \\
\text { value }\end{array}$} \\
\hline & \multicolumn{2}{|c|}{ Tidak } & \multicolumn{2}{|c|}{$\mathrm{Ya}$} & & \\
\hline & $f$ & $\%$ & $f$ & $\%$ & $f$ & \\
\hline Kurang & 17 & 81 & 4 & 19 & 21 & 0.007 \\
\hline Baik & 5 & 35.7 & 9 & 64.3 & 14 & \\
\hline Jumlah & 22 & 62.9 & 13 & 37.1 & 35 & \\
\hline
\end{tabular}

Tabel 3 menunjukkan bahwa sebagian besar responden mendapatkan dukungan keluarga yang kurang sebanyak 21 orang $(60 \%)$. Responden dengan dukungan keluarga yang kurang sebagian besar tidak memberikan ASI eksklusif sebanyak 17 (81\%). Sedangkan responden dengan dukungan keluarga yang baik sebagian besar memberikan ASI eksklusif sebanyak 9 (64.3\%). Hasil penelitian meunjukkan nilai $\rho$ value $=0.007<0,05$, artinya $\mathrm{Ha}$ diterima sehingga ada hubungan dukungan keluarga terhadap pemberian ASI Eksklusif di RW I Kelurahan Tambakharjo Kecamatan Semarang Barat Kota Semarang.

\section{PEMBAHASAN}

Hasil penelitian menunjukkan sebagian besar ibu memiliki pengetahuan yang kurang tentang ASI Eksklusif. Pengetahuan dapat dipengaruhi oleh beberapa faktor baik internal maupun eksternal. Salah satu faktor eksternal yang dapat mempengaruhi pengetahuan seseorang adalah paparan informasi. 
Informasi dapat diperoleh baik dari dalam maupun dari luar, salah satunya adalah informasi dari keluarga. Informasi yang diberikan keluarga tentang ASI Eksklusif dapat mempengaruhi pengetahuan ibu tentang ASI Eksklusif. Apabila informasi yang diberikan keluarga kurang tepat karena kurangnya informasi tentang ASI Eksklusif, maka informasi yang diberikan kepada ibu juga akan salah. Hal ini yang menyebabkan pengetahuan ibu tentang ASI Eksklusif masih kurang, karena informasi yang diberikan oleh keluarga tentang ASI Eksklusif masih kurang.

Hasil penelitian menunjukkan sebagian besar keluarga tidak mendukung ibu dalam pemberian ASI Eksklusif. Menurut Sarwono (2013), dukungan adalah suatu upaya yang diberikan kepada orang lain, baik moril maupun materil untuk memotivasi orang tersebut dalam melakukan kegiatan dalam hal ini adalah dukungan dalam pemberian ASI Eksklusif. Dukungan atau support dari orang lain atau orang terdekat sangat berperan dalam sukses tidaknya menyusui. Semakin besar dukungan yang didapatkan untuk terus menyusui maka akan semakin besar pula kemampuan untuk dapat bertahan terus untuk menyusui. Dukungan suami maupun keluarga sangat besar pengaruhnya. Suami dapat menguatkan motivasi ibu agar menjaga komitmen dengan ASI, tidak mudah tergoda dengan susu formula atau makanan lainnya. Suami juga harus membantu secara teknis seperti mengantar kontrol ke dokter atau bidan, menyediakan makanan bergizi, hingga memijit ibu yang biasanya cepat lelah.

Hasil penelitian menunjukkan sebagian besar ibu tidak memberikan ASI Eksklusif. Bagi sebagian ibu, menyusui merupakan tindakan yang alamiah dan naluriah. Oleh karena itu, mereka beranggapan bahwa menyusui tidak perlu dipelajari. Namun, kebanyakan ibu kurang menyadari pentingnya ASI sebagai makanan utama bayi. Mereka hanya mengetahui ASI adalah makanan yang diperlukan bayi tanpa memperhatikan aspek lainnya. Hasil uji statistik menggunakan uji Chi-Square menunjukkan hasil bahwa nilai $\rho$ value $=0.031<0.05$ sehingga $\mathrm{Ha}$ diterima, hal ini menunjukkan bahwa ada hubungan pengetahuan tentang ASI Eksklusif terhadap pemberian ASI Eksklusif.

Responden yang tidak memberikan ASI Eksklusif lebih banyak terdapat pada respoden dengan pengetahuan tentang ASI Eksklusif kurang yaitu (66.7\%) dibandingkan responden dengan pengetahuan tentang ASI Eksklusif baik yaitu (0\%). Dalam hal ini apabila ibu mempunyai pengetahuan yang kurang tentang ASI Eksklusif maka kemungkinan untuk memberikan ASI secara Eksklusif sangat kecil.

Hasil uji statistik menggunakan uji ChiSquare menunjukkan hasil bahwa nilai $\rho$ value $=0.007<0.05$ sehingga $\mathrm{Ha}$ diterima, hal ini menunjukkan bahwa ada hubungan dukungan keluarga terhadap pemberian ASI Eksklusif. Roesli (2014) menyatakan bahwa dukungan keluarga merupakan faktor eksternal yang paling besar pengaruhnya terhadap keberhasilan ASI Eksklusif. Adanya dukungan keluarga terutama suami maka akan berdampak pada peningkatan rasa percaya diri atau motivasi dari ibu dalam menyusui. Dukungan suami maupun keluarga sangat besar pengaruhnya. Seorang ibu yang kurang mendapatkan dukungan oleh suami dan keluarga bahkan ditakut-takuti dan dipengaruhi untuk beralih ke susu formula (Proverawati, 2010).

\section{KESIMPULAN DAN SARAN}

Ada hubungan pengetahuan tentang ASI Eksklusif dan dukungan keluarga dalam memberikan ASI Eksklusif terhadap pemberian ASI Eksklusif di RW I Kelurahan Tambakharjo Kecamatan Semarang Barat Kota Semarang. Tenaga kesehatan diharapkan melibatkan keluarga dalam memberikan KIE tentang ASI eksklusif agar ibu meningkatkan penge-tahuannya dan mendapatkan dukungan keluarga yang baik

\section{REFERENSI}

Dinas Kesehatan Kota Semarang. (2018). Profil Kesehatan 2018. Semarang: Dinas Kesehatan Kota Semarang.

Puskesmas dalam Pelaksanaan Program ASI Eksklusif di Kota Semarang". Jurnal 
Kesehatan Masyarakat, Vol.2, No.1. 2013.

http://ejournals1.undip.ac.id/index.php// $\mathrm{km}$

Proverawati, Atikah dan Eni Rahmawati. (2010). Kapita Selekta ASI \& Menyusui. Yogyakarta: Nuha Medika.

Roesli, Utami. (2014). Mengenal ASI Eksklusif. Jakarta: PT Pustaka Pembangunan Swadaya Nusantara.

Sarwono, S. W. (2013). Pengantar Umum Psikologi. Jakarta: Bulan Bintang.

Suririnah. (2009). Buku Pintar Merawat Bayi 012 Bulan; Panduan Bagi Ibu Baru Untuk Menjalani Hari - Hari Bahagia dan Menyenangkan Bersama Bayinya. Jakarta: Gramedia Pustaka Utama.

Survei Dasar Kesehatan Indonesia (SDKI).'2012. Jakarta.

Suradi, Rulina dan kristina (Ed.). (2004). Manajemen Laktasi. Jakarta: PERINASIA.

Suradi, Rulina dkk. (2010). Indonesia Menyusui. Jakarta: Badan Penerbit IDAI.

Wawan, A. (2011). Pengetahuan, Sikap dan Perilaku Manusia. Yogyakarta: Nuha Medika 